\title{
Deformability of Density Separated Red Blood Cells in Normal Newborn Infants and Adults
}

\author{
OTWIN LINDERKAMP, PAUL Y. K. WU, AND HERBERT J. MEISELMAN ${ }^{(35)}$ \\ Departments of Physiology and Biophysics and Pediatrics, University of Southern California, School of Medicine, Los \\ Angeles, California, USA
}

\begin{abstract}
Summary
The deformability of neonatal and adult red blood cells (RBC) was studied using both unseparated and density (i.e., age) fractionated RBC. Blood samples were obtained from 10 normal newborn infants (placental blood) and 10 adults. Deformability was measured by direct microscopic observation of RBC subjected to shear stresses of 2.5-500 dynes/ $\mathrm{cm}^{2}$ using a counter-rotating Rheoscope. There was no significant difference in deformability between unseparated neonatal and adult $\mathrm{RBC}$ at any shear stress. The 3\% least dense ("youngest") RBC showed significantly decreased hemoglobin concentrations (MCHC), increased volumes (MCV) and elevated deformability at any shear stress when compared to the $3 \%$ most dense ("oldest") cells, with the values for the unseparated RBC lying between these two extremes. The least dense neonatal RBC had a significantly lower MCHC and higher deformability than the least dense adult cells; however, the most dense neonatal $\mathrm{RBC}$ had lost more volume than the adult cells ( 33 versus $17 \%$ ), had a higher $\mathrm{MCHC}$, and were less deformable than the most dense adult cells. This indicates that the accelerated decrease in deformability of aging neonatal $\mathrm{RBC}$ is related to the more pronounced increase in MCHC, which is the principal determinant of the internal viscosity of the $R B C$
\end{abstract}

\section{Speculation}

The shortened survival time of neonatal red blood cells (RBC) is probably the consequence of accelerated aging of neonatal.RBC. Differences in biochemical composition and a decrease in some RBC activities, which are important for the maintenance of membrane integrity, cell volume, and deformability might be responsible for the faster loss of membrane fragments and deformability of neonatal RBC when compared to adult cells. These alterations presumably impede the ability of aging neonatal $\mathrm{RBC}$ to pass the narrow splenic slits, thus promoting their eventual destruction by macrophages.

Deformability of red blood cells (RBC) is defined as their ability to deform (i.e., to assume new shapes) in response to forces applied on the cell (3). This empirical definition has important clinical implications. In vivo, RBC need to deform at two levels: (1) adaptation to high shear forces in large vessels with rapid flow and (2) passage through narrow capillaries and splenic slits with diameters less than that of the resting $\operatorname{RBC}(3,13,25)$. Failure of the $\mathrm{RBC}$ to deform sufficiently can therefore result in disturbed large and small vessel circulation and in $\mathrm{RBC}$ damage. At high hematocrit, the deformability of RBC is particularly crucial because blood viscosity exhibits a larger increase with increasing hematocrit when RBC deformability is impaired (3). Therefore, decreased RBC deformability would further increase the danger of polycythemia, a frequent occurrence in newborn infants (17, 23).

Deformability of neonatal RBC has been assessed by both filtration techniques and viscometry. Most studies on the filtration rate of neonatal $\mathrm{RBC}$ have shown that they are less filterable than adult cells $(2,8,29)$ thus suggesting that they are less deformable; however, Bergqvist et al. (1) found no difference in filterability between neonatal and adult RBC. Viscometry of RBC, studied under controlled conditions (nonaggregating suspending medium, constant hematocrit), did not demonstrate significant differences between neonatal and adult $\operatorname{RBC}(7,16)$, thereby suggesting that there is no difference in deformability. Different forces exerted by filtration and viscometry may account for the apparent contradiction of previous findings (3). In addition, neither filtration nor viscometry allow direct measurement of RBC deformation and thus provide only estimates of cellular deformability.

The life span of neonatal RBC is about 60 days, which is onehalf that of adult cells (21). Because the spleen functions as a small-pore filter, which requires marked deformation of passing $\mathrm{RBC}$, it has been suggested that the shortened life span of neonatal $\mathrm{RBC}$ is a result of decreased deformability of the average circulating cell (14). Another possibility is that young neonatal RBC are normally deformable but, as they age, they lose their deformability faster than adult cells.

During in vivo aging, $\mathrm{RBC}$ lose membrane fragments and water, leading to a decrease in volume and an increase in density (15). The progressive increase in density of $\mathrm{RBC}$ with increasing age is widely utilized to separate adult $\mathrm{RBC}$ according to their age. Besides these structural alterations, $\mathrm{RBC}$ aging is accompanied by inactivation of several enzymes $(6,9,20,30)$. When neonatal RBC are separated by density, they show differences similar to adult cells in various fractions $(6,20)$. It appears likely that neonatal $\mathrm{RBC}$ can also be separated according to their age using appropriate centrifugation methods.

In adults, age-dependent decreases in RBC deformability have been demonstrated by increased viscosity $(12,28)$, impaired filterability (28), decreased elongation under high shear $(12,22)$ and increased pressure required to aspirate the entire RBC into micropipettes (13). Deformability studies of age-separated neonatal RBC do not appear to exist in the literature.

The present investigation was designed to study the deformability of unfractionated and density (i.e., age) separated RBC from newborn infants and adults. De ormability measurements were made using direct microscopic observation of $\mathrm{RBC}$ subjected to a wide range of shear forces by means of a counter-rotating Rheoscope (25). Our results indicate no significant differences in deformability between unfractionated neonatal and adult $\mathrm{RBC}$; however, the least dense ("youngest") and most dense ("oldest") neonatal $\mathrm{RBC}$ differed markedly in their deformability from corresponding fractions of adult cells.

\section{MATERIALS AND METHODS}

Placental blood samples from ten healthy newborn infants with gestational ages of 39-41 wk and birth weights of 3360-3640 g were studied with approval of the University of Southern California Human Subjects Research Committee. Immediately after 
cord-clamping, $10 \mathrm{ml}$ of blood were collected from the placenta into heparin $(5 \mathrm{IU} / \mathrm{ml})$. Adult blood samples were collected from ten healthy laboratory personnel via venipuncture into heparin. All measurements were made at room temperature $\left(22 \pm 1^{\circ} \mathrm{C}\right)$ within $4 \mathrm{~h}$ after collection. Part of each neonatal and adult blood sample was separated into two fractions using a centrifugal technique similar to that described in other studies $(12,15,22)$. Whole blood was placed into $4-\mathrm{mm}$ internal diameter by $47-\mathrm{mm}$ long plastic tubes and centrifuged for $15 \mathrm{~min}$ at $12,000 \times \mathrm{g}$. After centrifugation, the length of the red cell column was accurately measured and each tube was then cut at the border between the buffy coat and the RBC; the top 3\% of the cells was then carefully removed. The tube was cut again very close to the lower end and the bottom $3 \%$ of the cells removed. Top and bottom fractions thus contained $3 \%$ of the least and most dense cells, respectively.

A portion of the top and bottom RBC and of whole blood (i.e., unseparated cells) was diluted into phosphate buffered saline (PBS), $0.030 \mathrm{M} \mathrm{KH}_{2} \mathrm{PO}_{4}+\mathrm{Na}_{2} \mathrm{HPO}_{4}, 290 \mathrm{mOsm} / \mathrm{kg}, \mathrm{pH} 7.40$ at $25^{\circ} \mathrm{C}$ ), for analysis of hematologic indices. Another portion of the RBC was suspended at hematocrits of $1-2 \%$ in PBS containing 20 $\mathrm{g} / \mathrm{dl}$ of dextran T-70 (Pharmacia, Uppsala, Sweden) for deformability measurements. The osmolality of these dextran solutions was $290 \pm 5 \mathrm{mOsm} / \mathrm{kg}$ and the viscosity was $21.2 \mathrm{cP}$ at $25^{\circ} \mathrm{C}$.
Note that this increase in the suspending medium viscosity via dextran is necessary in order to achieve cellular deformation in the Rheoscope $(19,25)$.

RBC counts and mean cell volumes ( $\mathrm{MCV}$ and sample S.D.) were determined with an Electrozone-Celloscope (Particle Data Inc., Elmhust, IL) equipped with a $76-\mu \mathrm{m}$ orifice and operating with a $20 \%$ rejection level to eliminate the artifact caused by nonaxial transit of the RBC (4). Hemoglobin concentrations were determined spectrophotometrically by the cyanmethemoglobin method. Mean corpuscular hemoglobin $(\mathrm{MCH})$ was calculated as ratio of the hemoglobin concentration and the $\mathrm{RBC}$ count. The mean corpuscular hemoglobin concentration $\left(\mathrm{N}_{i} \mathrm{CHC}\right)$ is the $\mathrm{MCH}$ divided by MCV.

The deformability of single cells was observed and measured using a counter-rotating, cone-plate Rheoscope (25), which was mounted on an inverted microscope (Leitz Diavert, Leitz, Wetzlar, Germany) equipped with a $40 \times$ (numerical aperture $=0.70$ ) phase contrast objective. The cell suspensions placed in the gap between the plate and the $1.5^{\circ}$ cone were subjected to 10 different shear stresses from $0-500$ dynes $/ \mathrm{cm}^{2}$. Erythrocytes aligned in the stationary layer of the shear field were observed at a radial distance of $1200 \mu \mathrm{m}$ from the center of rotation. Three photomicrographs of the cells (Fig. 1) were taken at each of the shear
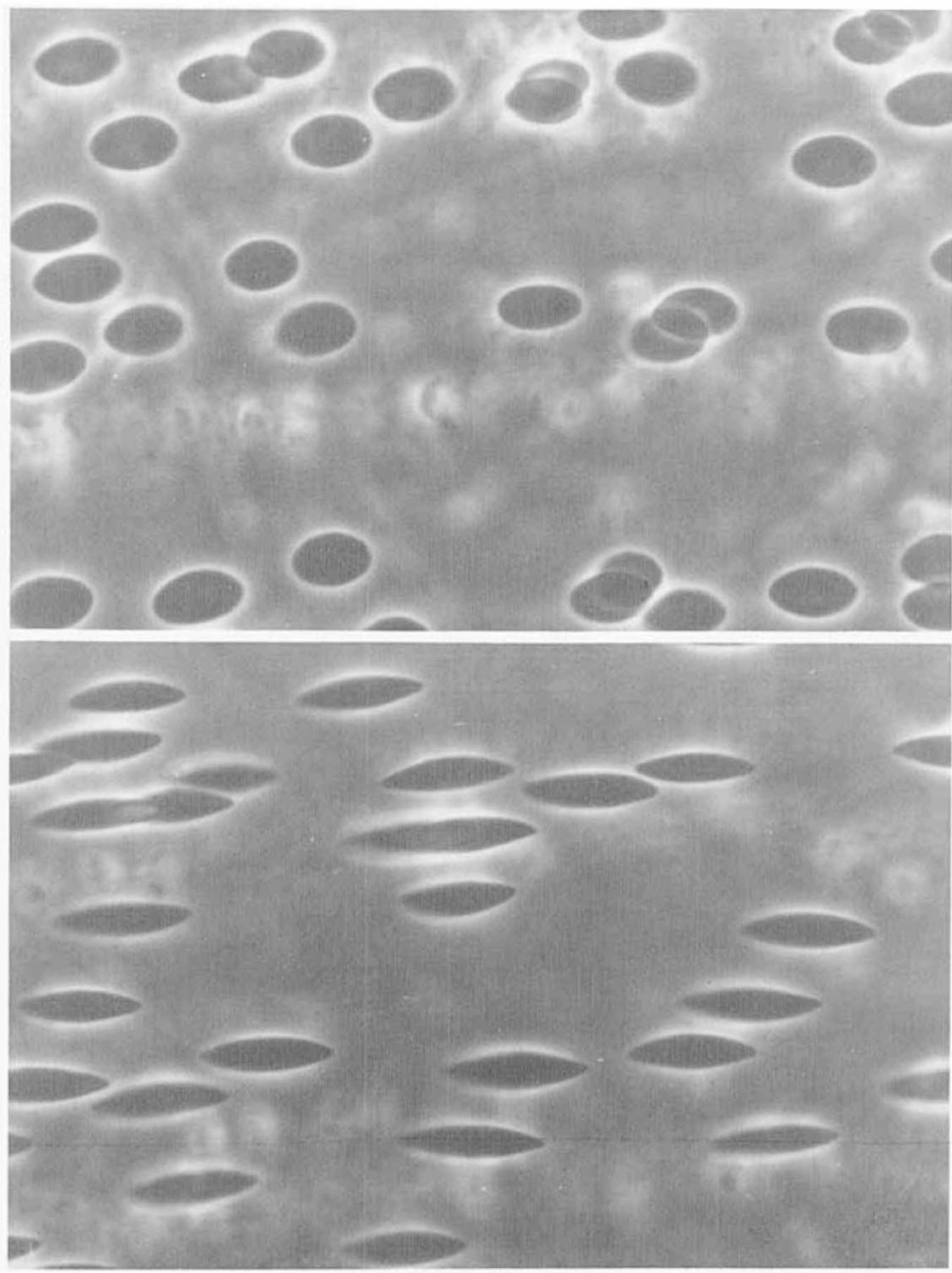

Fig. 1. Deformation of unfractionated neonatal red blood cells in the cone-plate rheoscope. The cells were suspended in $21.2 \mathrm{cP}$ isotonic dextran solution and subjected to fluid shear stresses of: 7.5 dynes $/ \mathrm{cm}^{2}$ (top panel) and 500 dynes $/ \mathrm{cm}^{2}$ (bottom panel). 
stresses using high contrast film (Kodak 2415) and short duration flash illumination. The shear stresses were applied in a randomized order. The deformation (D) of 40 completely visible cells was determined from these photomicrographs (i.e., 12-14 cells per photomicrograph). $\mathrm{D}$ is defined as the ratio $(\mathrm{L}-\mathrm{W}) /(\mathrm{L}+\mathrm{W})$, where $\mathrm{L}$ is the projected length of the cell in the direction of flow and $\mathrm{W}$ is its width perpendicular to the direction of flow.

$D$ values increase with increasing cellular deformation and approach a limiting value at high shear stresses. The value of $D$ is zero in the absence of deformation. The advantage of the Rheoscope as a microrheologic technique is that it allows the deformation of single $\mathrm{RBC}$ to be determined whereas other methods (e.g., micropore filtration) only provide average information for a RBC population. The Rheoscope method is sensitive enough to detect slight alterations of $\mathrm{RBC}$ deformability for entire cell populations as well as the presence of a subpopulation of poorly deformable cells $(19,22)$. The latter ability depends on the fraction of abnormal RBC and on the total number of cells studied.

Statistical analyses were performed to test for differences in measurements between top and bottom RBC. These tests were done separately for the two groups (neonates and adults) and used a two-tailed paired $t$ test with 9 degrees of freedom and a twotailed unpaired $t$ test with 18 degrees of freedom. Further analyses were performed to test for differences between the neonates and the adults using a two-tailed unpaired $t$ test with 18 degrees of freedom. For the unpaired $t$ tests, two S.D. of the MCV and the deformability data were used: (1) the S.D. of the means of the two groups, each containing 10 samples and (2) the S.D. of the single measurements done in each group (e.g., 400 deformability measurements: $40 \mathrm{RBC}$ from each of the 10 samples). The second S.D. reflects the spread of the individual $\mathrm{RBC}$ in all 10 samples and is therefore usually larger than the first S.D., which reflects only the spread of the sample means. Nevertheless, we used 18 degrees of freedom for both tests because the number of degrees of freedom should be based on the number of samples rather than on the total number of observations because of possible interindividual differences (27).

\section{RESULTS}

Red blood cell (RBC) hematologic indices and the RBC deformability results at selected shear stresses are shown in Table 1 and Figure 2. In both the neonates and the adults, the MCV of the bottom RBC was significantly $(P<0.001)$ lower, and the MCHC was significantly $(P<0.001)$ higher than the top cells. The MCH did not change significantly with increasing density of the adult RBC but was nearly significantly $(P<0.10)$ decreased in the bottom cells of the neonates when compared with their top cells.

An overview of the RBC deformation-shear stress results for density (age) separated and unfractionated neonatal and adult $\mathrm{RBC}$ is presented in Figure 3. The deformability of the bottom $\mathrm{RBC}$ was significantly lower than the top $\mathrm{RBC}$ in both groups.

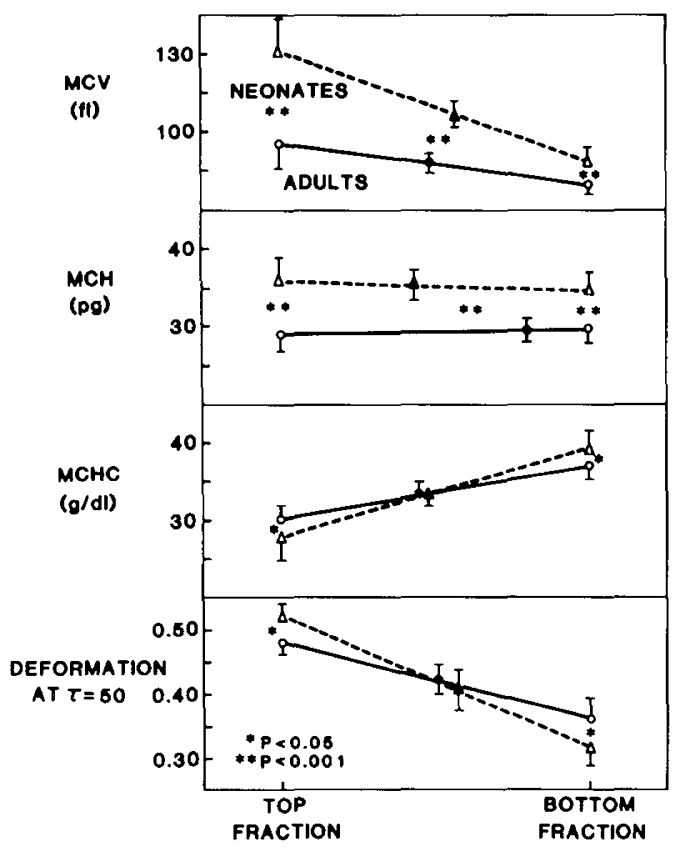

Fig. 2. Hematologic and deformability data of neonatal and adult red blood cells $(\mathrm{RBC})$. The solid data points on the lines represent the unfractionated RBC. Their position on the lines were determined merely by the magnitude of the measured variables. Note that the mean cell volumes (MCV) and deformation of the neonatal RBC decrease more and that the mean corpuscular hemoglobin concentration (MCHC) increases more with increasing density than the adult cells.

Table 1. Hematologic and deformability data for neonatal and adult red blood cells $(R B C)^{1}$

\begin{tabular}{|c|c|c|c|c|c|c|}
\hline & \multirow{2}{*}{$\begin{array}{l}\text { Mean cell } \\
\text { volume } \\
(\mathrm{fl})\end{array}$} & \multirow{2}{*}{$\begin{array}{c}\text { Mean corpuscular } \\
\text { hemoglobin } \\
(\mathrm{pg})\end{array}$} & \multirow{2}{*}{$\begin{array}{l}\text { Mean corpuscular } \\
\text { hemoglobin } \\
\text { concentration } \\
(\mathrm{g} / \mathrm{dl})\end{array}$} & \multicolumn{3}{|c|}{ Deformability (at shear stress in dynes $/ \mathrm{cm}^{2}$ ) } \\
\hline & & & & 5 & 50 & 500 \\
\hline \multicolumn{7}{|c|}{ Unfractionated $\mathrm{RBC}$} \\
\hline A & $\begin{aligned} 88.2 & \pm 3.2 \\
( & \pm 14.8)\end{aligned}$ & $29.5 \pm 1.4$ & $33.4 \pm 1.2$ & $\begin{array}{r}0.133 \pm 0.026 \\
( \pm 0.065)\end{array}$ & $\begin{array}{r}0.421 \pm 0.023 \\
( \pm 0.069)\end{array}$ & $\begin{array}{r}0.569 \pm 0.026 \\
( \pm 0.057)\end{array}$ \\
\hline $\mathrm{N}$ & $\begin{array}{l}106.9 \pm 4.7^{3} \\
( \pm 23.5)^{2}\end{array}$ & $35.5 \pm 1.9^{3}$ & $33.2 \pm 1.4$ & $\begin{array}{r}0.139 \pm 0.024 \\
( \pm 0.056)\end{array}$ & $\begin{array}{r}0.403 \pm 0.031 \\
( \pm 0.042)\end{array}$ & $\begin{array}{r}0.566 \pm 0.036 \\
( \pm 0.033)\end{array}$ \\
\hline \multicolumn{7}{|c|}{ Top RBC } \\
\hline A & $\begin{aligned} & 96.4 \pm 5.2 \\
&( \pm 16.4)\end{aligned}$ & $29.1 \pm 1.7$ & $30.2 \pm 1.9$ & $\begin{array}{r}0.175 \pm 0.020 \\
( \pm 0.046)\end{array}$ & $\begin{array}{r}0.482 \pm 0.021 \\
( \pm 0.036)\end{array}$ & $\begin{array}{r}0.619 \pm 0.020 \\
( \pm 0.028)\end{array}$ \\
\hline $\mathrm{N}$ & $\begin{array}{r}131.2 \pm 13.0^{3} \\
( \pm 31.8)^{2}\end{array}$ & $36.1 \pm 2.7^{3}$ & $27.7 \pm 2.8^{2}$ & $\begin{array}{r}0.207 \pm 0.024^{2} \\
( \pm 0.054)\end{array}$ & $\begin{array}{r}0.520 \pm 0.025^{2} \\
( \pm 0.040)^{2}\end{array}$ & $\begin{array}{r}0.653 \pm 0.028^{2} \\
( \pm 0.030)^{2}\end{array}$ \\
\hline \multicolumn{7}{|c|}{ Bottom RBC } \\
\hline A & $\begin{aligned} & 79.6 \pm 3.4 \\
&( \pm 14.0)\end{aligned}$ & $29.6 \pm 1.6$ & $37.2 \pm 1.8$ & $\begin{array}{r}0.076 \pm 0.021 \\
( \pm 0.056)\end{array}$ & $\begin{array}{r}0.362 \pm 0.034 \\
( \pm 0.051)\end{array}$ & $\begin{array}{r}0.518 \pm 0.035 \\
( \pm 0.072)\end{array}$ \\
\hline $\mathrm{N}$ & $\begin{aligned} & 88.5 \pm 5.0^{3} \\
&( \pm 20.7)\end{aligned}$ & $34.7 \pm 2.2^{3}$ & $39.3 \pm 2.3^{2}$ & $\begin{array}{r}0.054 \pm 0.018^{2} \\
( \pm 0.051)\end{array}$ & $\begin{array}{r}0.314 \pm 0.028^{2} \\
( \pm 0.048)^{2}\end{array}$ & $\begin{array}{r}0.446 \pm 0.029^{3} \\
( \pm 0.077)^{2}\end{array}$ \\
\hline \multicolumn{7}{|c|}{ Top/bottom } \\
\hline A & $1.21 \pm 0.07$ & $0.98 \pm 0.06$ & $0.81 \pm 0.05$ & $2.45 \pm 0.64$ & $1.34 \pm 0.09$ & $1.20 \pm 0.06$ \\
\hline $\mathrm{N}$ & $1.48 \pm 0.13^{3}$ & $1.04 \pm 0.06$ & $0.71 \pm 0.06^{3}$ & $4.17 \pm 1.17^{3}$ & $1.67 \pm 0.19^{3}$ & $1.47 \pm 0.08^{3}$ \\
\hline
\end{tabular}

${ }^{1}$ Values represent mean \pm 1 S.D. Note that the first S.D. reflects the spread of the 10 sample means, whereas the values in parentheses reflect the spread of the red cell populations. A, adults and $\mathrm{N}$, neonates.

${ }^{2} p<0.05$ when compared to adult red cells (two-tailed unpaired $t$ test, 18 degrees of freedom).

${ }^{3} p<0.001$ when compared to adult red cells (two-tailed unpaired $t$ test, 18 degrees of freedom). 


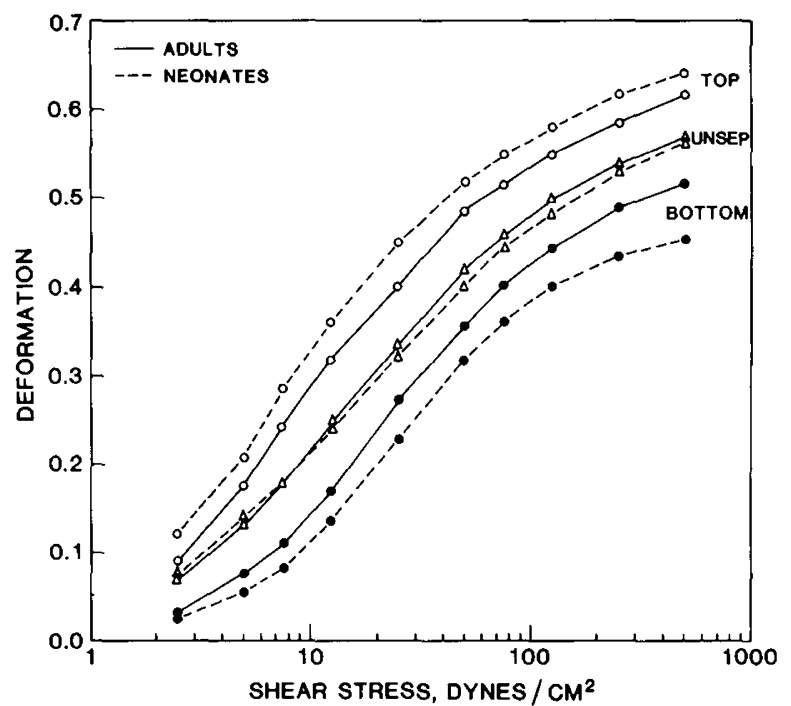

Fig. 3. Deformation of unseparated and density-fractionated neonatal and adult red blood cells plotted against shear stress. Note that the neonatal cells in the top fraction deform more and that the neonatal cells in the bottom fraction deform less than corresponding fractions of adult cells.

The significance was high $(P<0.001)$ at each shear stress and in each of the two groups independent of whether a two-tailed paired $t$ test (differences between the 10 sample means) or a two-tailed unpaired $t$ test (comparison of the means and S.D. of the $400 \mathrm{RBC}$ in each fraction) was used.

$\mathrm{MCV}$ and $\mathrm{MCH}$ of the neonatal $\mathrm{RBC}$ were significantly increased in all three cell populations when compared to the corresponding adult RBC (Table 1). The MCHC was similar in the unseparated RBC of both groups; however, the MCHC of the neonatal $\mathrm{RBC}$ in the top fraction was significantly lower $(P<$ 0.05 ) when compared to the top cells of the adults. On the other hand, the $\mathrm{MCHC}$ of the neonatal $\mathrm{RBC}$ in the bottom fraction was significantly $(P<0.05)$ higher when compared to the bottom cells of the adults.

The deformability of the unfractionated RBC did not show significant differences between the neonates and the adults at any shear stress; however, the deformability of the neonatal RBC in the top and bottom fractions were markedly different when compared to the adult $\mathrm{RBC}$ in the corresponding fractions. The deformability of the neonatal $\mathrm{RBC}$ in the top fraction was higher whereas that of the bottom cells was lower than the adult RBC of the same fractions (Fig. 2 and 3). These differences between neonatal and adult $\mathrm{RBC}$ in the most and least dense cell fractions were significant $(P<0.05)$ at any shear stress, when the S.D. of the 10 samples means in each group were used. Comparisons by using the higher S.D. of the 400 measurements done in each group revealed significant $(P<0.05)$ differences only when the shear stress was 25 dynes $/ \mathrm{cm}^{2}$ or higher.

The above mentioned results show that the differences between top and bottom RBC are larger in the neonates than in the adults. These differences become more evident when expressed as ratios (Table 1). The MCV ratios and the deformability ratios were significantly $(P<0.001)$ higher in the newborns when compared to the adults. The MCHC ratio was lower in the neonates. The $\mathrm{MCH}$ ratio was nearly significantly $(P<0.10)$ higher in the neonates than in the adults. These results thus show that the least dense neonatal $\mathrm{RBC}$ have a lower hemoglobin concentration and are more deformable than the least dense adult $\mathrm{RBC}$; however, the most dense neonatal $\mathrm{RBC}$ have lost more volume, have a higher hemoglobin concentration and are less deformable than the most dense adult RBC.

\section{DISCUSSION}

The separation techniques employed in the present study provided adequate cell separation for both the neonatal and adult samples as shown by the decreased MCV and increased MCHC of the $\mathrm{RBC}$ in the bottom fraction compared to the top fraction. In the adults, the ratio of the MCV values of the top to the bottom $\mathrm{RBC}$ was 1.21 and the corresponding MCHC ratio was 0.81 (Table $1)$, which is in agreement with other studies $(6,15,28)$. In the neonates, the MCV ratio was 1.48 and the MCHC ratio was 0.71 . This indicates that the youngest neonatal RBC contain less hemoglobin and more water in relation to their volume than the youngest adult $\mathrm{RBC}$; however, neonatal $\mathrm{RBC}$ seem to lose twice as much volume during aging as adult cells. This volume loss appears to consist mainly of fluid because the hemoglobin content (MCH) did not change markedly with age. Very low MCHC values in the least dense neonatal RBC and high values in the most dense neonatal cells have also been shown by Gahr et al. (6) using an ultracentrifugation method. The wider range in $\mathrm{MCHC}$ values corresponds to a wider range of densities for neonatal $\mathrm{RBC}$ $(5,6)$.

This study demonstrates that the deformability of unseparated neonatal RBC is not different from unseparated adult RBC when measured with the Rheoscope. These results appear to be contradictory to those obtained by filtration studies, which indicated markedly decreased filterability of neonatal $\operatorname{RBC}(2,8,29)$. Filterability of $\mathrm{RBC}$ is influenced by cell geometry $(3,31)$. Neonatal $\mathrm{RBC}$ have the same excess surface area and shape as adult cells; however, the minimal cylindrical diameter (i.e., the minimum diameter tube which a cell can enter without loss of volume) of neonatal $\mathrm{RBC}$ is larger than that for adult RBC (18). The impaired filterability of neonatal $\mathrm{RBC}$ may be the result of specific differences in cell geometry.

A decrease in cellular deformability of adult $\mathrm{RBC}$ with age has been reported by several investigators $(12,13,22,28)$. The results described herein confirm these observations and show, in addition, that neonatal $\mathrm{RBC}$ also become less deformable as they age. Moreover, the least and most dense neonatal RBC showed a significantly different deformability compared to adults; the least dense neonatal $\mathrm{RBC}$ deformed more and the most dense neonatal cell deformed less than the adult $\mathrm{RBC}$ in the corresponding fractions (Fig. 2 and 3).

The deformability of RBC is determined by four factors (19): (1) the excess membrane surface area beyond that required to enclose the cell volume; (2) cellular morphology (e.g., echinocyte or stomatocyte formation); (3) the membrane mechanical properties (e.g., membrane viscosity and elastic shear modulus); and (4) the viscosity of the cellular contents (internal viscosity) which is essentially determined by the $\mathrm{MCHC}(22,24)$. RBC deformability as determined by the Rheoscope is influenced by all four of these factors $(22,25)$.

Aging adult $\mathrm{RBC}$ have decreased excess surface area, increased membrane viscosity (15) and a high internal viscosity resulting from the elevated MCHC (22). It can be calculated from the data given by Ross and Minton (24) that the viscosity of hemoglobin at the concentrations measured in unfractionated neonatal and adult $\mathrm{RBC}$ is about $10 \mathrm{cP}$. The top neonatal and adult $\mathrm{RBC}$ have a calculated hemoglobin viscosity of 5 and $7 \mathrm{cP}$, respectively. In the bottom fraction, the calculated hemoglobin viscosity is $26 \mathrm{cP}$ for the neonatal $\mathrm{RBC}$ and $18 \mathrm{cP}$ for the adult cells. It appears reasonable to assume that the differences in deformability between neonatal and adult $\mathrm{RBC}$ fractions are influenced by the differences in $\mathrm{MCHC}$; however, the anticipated decrease in $\mathrm{RBC}$ deformability resulting from the larger internal viscosity of the older neonatal $\mathrm{RBC}$ versus the older adult cells is less than the difference shown in Table 1 (22). Other factors, such as changes in excess surface area, cellular morphology or membrane mechanical properties may also contribute to the lower deformability of the oldest neonatal RBC.

Repeated loss of small membrane fragments, which is another important factor in the aging process of the $\operatorname{RBC}(13,15)$, occurs as a result of frequent shear deformation in the circulation (31). Membrane fragmentation is favored by ATP-depletion (13), peroxidation of membrane components (4) or by "intrinsic" defects of the membrane (31). Neonatal RBC could be more affected by all three of these factors: ATP-depletion occurs faster during brief 
incubation (20); neonatal RBC are more prone to oxidant-induced injury $(11,20)$ and their mechanical fragility is increased (26). It thus appears possible that the aging process of neonatal $\mathrm{RBC}$ is accelerated. This hypothesis is supported by the finding that the activity of some strongly age-dependent $\mathrm{RBC}$ enzymes declines more rapidly in neonatal $\mathrm{RBC}$ when compared to adult cells $(6$, 20).

Whatever the mechanism for accelerated aging of neonatal $\mathrm{RBC}$, the decreased deformability of the oldest neonatal RBC (which are in fact much younger than the oldest adult RBC) might impair their ability to pass through the narrow splenic slits. Prolonged stay in this acidic and energy-poor splenic environment presumably promotes ATP-depletion and swelling of RBC, which decreases RBC deformability further $(19,31)$. It appears unlikely that impaired deformability alone causes literal trapping of cells in the splenic network. Altered deformability might, however, decrease the rate of passage through the reticuloendothelial system thereby aiding in recognition of effete cells by macrophages (10).

\section{REFERENCES AND NOTES}

1. Bergqvist, G., Bygdeman, S., and Rylander, E.: Deformability of fetal erythrocytes. Bibl. Anat., 16: 510 (1977)

2. Buchan, P. C.: Evaluation and modification of whole blood filtration in the measurement of erythrocyte deformability in pregnancy and the newborn. $\mathrm{Br}$. J. Haematol., 45: 97 (1980).

3. Chien, S.: Determinants of blood viscosity and red cell deformability. Scand. J. Clin. Lab. Invest., 40: (Suppl. 156): 7 (1981).

4. Corry, W. D., Meiselman, H. J., and Hochstein, P.: t-butyl hydroperoxideinduced changes in the physicochemical properties of human erythrocytes. Biochim. Biophys. Acta, 597: 224 (1980).

5. Danon, Y., Kleimann, A., and Danon, D.: The osmotic fragility and density distribution of erythrocytes in the newborn. Acta Haematol., 43: 242 (1970).

6. Gahr, M., Meves, H., and Schröter, W.: Fetal properties in red blood cells of newborn infants. Pediatr. Res., 13: 1231 (1979).

7. Giliberti, P., Tuchschmid, P., and Duc, G.: Viscosity and ATP-depletion by fluoride in adult and newborn red-blood cells. Pediatr. Res (Abstract), 15: 1180 (1981).

8. Gross, G. P. and Hathaway, W. E.: Fetal erythrocyte deformability. Pediatr. Res., 6: 593 (1972)

9. Kahn, A., Boyer, C.. Cottreau. D., Marie, J., and Boivin, P.: Immunologic study of the age related loss of activity of six enzymes in the red cells from newborn infants and adults. Evidence for a foetal type of erythrocyte phosphofructokinase. Pediatr. Res., 11: 271 (1977).

10. Kay, M. M. B.: Mechanism of removal of senescent cells by human macrophages in situ. Proc. Natl. Acad. Sci., 72: 3521 (1975)

11. Kleihauer, E., Bernau, A., Betke, K.. Keller, M., Kohne, E., and Riegel, K. Heinzkörperbildung in Neugeborenenerythrozyten I. In-vitro-Studien über experimentelle Bedingungen und den Einfluss von Austauschtransfusionen. Acta Haematol.. 43: 333 (1970).

12. Klose. H. J., Kelson, S., Linderkamp, O., Riegel, K.. and Betke, K.: Microrheology of young and old red cells in childhood iron deficiency and hemolytic anemias. Bibl. Anat., 20: 178 (1981).

13. La Celle, P. L. Kirkpatrick, F. H., Udkow, M. P., and Arkin, B.: Membrane fragmentation and $\mathrm{Ca}^{++}$-membrane interaction: potential mechanisms of shape change in the senescent red cell. In: M. Bessis. R. I. Weed, P. F. Leblond: Red cell shape, p. 69 (Springer, New York, Heidelberg, Berlin, 1973).

14. Landaw, S. A.: Decreased survival and altered membrane properties of red blood cells (RBC) in the newborn rat. Pediatr. Res. (Abstract), 70: 395 (1978).

15. Linderkamp, O., and Meiselman, H. J.: Geometric and membrane mechanical properties of density-separated human red cells. Blood. 59: 1121 (1982).

16. Linderkamp, O., Meiselman, H. J., Wu, P. Y. K., and Miller, F. C.: Blood and plasma viscosity and optimal hematocrit in the normal newborn infant. Clin. Hemorheol., l: 575 (1981).

17. Linderkamp. O.. Strohhacker, I., Versmold, H. T., Klose, H., Riegel. K. P.. and Betke, K.: Peripheral circulation in the newborn: Interaction of peripheral blood flow, blood pressure, blood volume and blood viscosity. Eur. J. Pediatr., 129: 73 (1978).

18. Linderkamp, O., Wu, P. Y. K., and Meiselman, H. J.: Geometry of neonatal and adult red blood cells. Pediatr. Res. (in press).

19. Meiselman. H. J.: Morphological determinants of red cell deformability. Scand. J. Clin. Lab. Invest.. 41: (Suppl. 156): 27 (1981).

20. Oski, F. A. and Komazawa, M.: Metabolism of the erythrocytes of the newborn infant. Semin. Hematol., 12: 209 (1975).

21. Pearson, H. A.: Life-span of the fetal red blood cell. Pediatrics, 70: 166 (1967).

22. Pfafferott, C., Wenby, R. B., and Meiselman, H. J.: Morphologic and internal viscosity aspects of $\mathrm{RBC}$ rheologic behavior. Blood Cells, 8: 65 (1982).

23. Ramamurthy, R. S. and Brans, Y. W.: Neonatal polycythemia: I. Criteria for diagnosis and treatment. Pediatrics, 68: 168 (1981).

24. Ross, P. D. and Minton, A. P.: Haro quasipherical model for the viscosity of hemoglobin solutions. Biochem. Biophys. Res. Commun., 76: 971 (1977).

25. Schmid-Schönbein, H.: Microrheology of erythrocytes, blood viscosity and the distribution of blood flow in the microcirculation. Int. Rev. Physiol.. 9: 1 (1976).

26. Sjölin, S.: The resistance of red cells in vitro. Acta Paediatr. Scand., 43: (Suppl. 98): 1 (1954)

27. Snedecor, G. W. and Cochran, W. G.: Statistical methods. 6th ed. (Iowa State University Press, Ames, 1967).

28. Tillmann, W., Levin, C., Prindull, G., and Schröter, W.: Rheological properties of young and aged human erythrocytes. Klin. Wochenschr., 58: 569 (1980).

29. Tillmann, W., Zabel, U., Lakomek, M., and Schröter, W.: Influence of the fluidity of hemoglobin $F$ on the flexibility of red cells of newborn and older infants. Bibl. Anat., 20: 222 (1981).

30. Travis, S. F. and Garvin, J. H.: In vivo lability of red cell phosphofructokinase in term infants: the possible molecular basis of the relative phosphof ructokinase deficiency in neonatal red cells. Pediatr. Res., 11: 1159 (1977).

31. Waugh, R. E. and La Celle, P. L.: Abnormalities in the membrane material properties of hereditary spherocytes. J. Biomech. E., 102: 240 (1980).

32. The authors wish to thank Rosalinda Wenby, B. S., for her technical assistance and Vivian M. Vargas, B. A., for processing the films and prints.

33. Dr. Linderkamp is a recipient of a Research Award from the Deutsche Forschungsgemeinschaft ( $\mathrm{Li} 291 / 2-1)$.

34. This research was supported by grants from the National Institutes of Health (HL15722 and HL15162).

35. Requests for reprints should be addressed to: H. J. Meiselman, Sc. D., Department of Physiology and Biophysics, USC School of Medicine. 2025 Zonal Ave., Los Angeles, CA. 90033.

36. Received for publication January 8, 1982

37. Accepted for publication May 6, 1982. 